\title{
TURISMO DE MASSAS VERSUS PROTEÇÃO DA ORLA COSTEIRA NO ALGARVE: UMA REFLEXÃO
}

\author{
JOANA GASPAR DE FREITAS ${ }^{(1)} \&$ JOÃO ALVEIRINHO DIAS ${ }^{(2)}$
}

Resumo:

\begin{abstract}
Nenhum outro trecho da costa portuguesa reflete melhor as consequências da ocupação humana do litoral como o Algarve. $\mathrm{O}$ isolamento da região permitiu que mantivesse até ao século XX um conjunto de características naturais e modos de vida tradicionais já desaparecidos noutros locais. Entre 1960-80, o Algarve conheceu um desenvolvimento sem precedentes devido à afluência de turistas estrangeiros e portugueses, graças à melhoria das condições de vida após o 25 de Abril. A explosão urbanística que acompanhou o apogeu do turismo de massas traduziu-se num crescimento desmesurado, em que os interesses económicos se sobrepuseram ao bem comum. Os planos de ordenamento traçados nos anos de 1960 não chegaram a ser implantados e no período conturbado que se seguiu à Revolução de Abril não houve controlo da construção. Quando os primeiros instrumentos de ordenamento do território foram aprovados (década de 1990) a situação existente e os direitos estabelecidos obrigaram ao sancionamento de irregularidades, pondo em causa a prática de uma boa gestão do uso do solo. A ocupação intensa desta zona costeira em tão curto tempo provocou desequilíbrios nos sistemas naturais, contribuindo para a degradação da paisagem e para colocar em risco a presença humana nos trechos mais afetados.

Palavras-chave: História, Algarve, Zona Costeira, Turismo, Planos de Ordenamento
\end{abstract}

Abstract:

Mass Tourism versus Coastal Zone Protection in the Algarve: a reflection.

The Algarve, in the south of Portugal, is a good example of the impacts of human settlement in the seashore. Far away from the main urban centers, the region was able to keep until the middle of the twentieth century a number of natural features and traditional ways of life already disappeared in other places. Between 1960-80, the Algarve experienced an unprecedented development due to the influx of foreign tourists and Portuguese, especially after the Democratic Revolution of 1974 that improved living conditions. Excessive urban growth followed mass tourism and economic interests overlap the common good. The development plans drawn in the 1960s were never put into practice and in the troubled years that followed the Democratic Revolution there was no control of the building.

When the first spatial planning instruments were adopted (in the 1990s) the existing situation and the rights established in the past forced the sanctioning of irregularities, calling into question the practice of good management concerning land use. The increasing of human activity in the seashore in such a short time and with such intensity caused imbalances in coastal natural systems, contributing to the degradation of the landscape and endangering human presence in the most affected parts.

Keywords: History, Algarve, Coastal Zone, Tourism, Management Plans

Received: 15 March, 2016; Accepted: 25 April, 2016

\section{INTRODUÇÃO}

O Algarve é hoje o principal destino turístico dos portugueses e de um número significativo de cidadãos de outros países europeus. É um fenómeno recente, já que, por falta de transportes e de boas vias de comunicação, o Algarve permaneceu relativamente isolado do resto do país durante muito tempo. Manteve-se, assim, arredado das mutações económicas, sociais, demográficas, urbanísticas e ambientais, que a afirmação da vilegiatura marítima no século XIX fez despontar nos litorais da Europa e na costa ocidental portuguesa a norte do Tejo. A região algarvia só integrou os circuitos do turismo internacional em finais da década de 1950, quando, após a II Guerra Mundial, restabelecidas as economias, houve condições para retomar o interesse pelas viagens. Assistiu-se, então, a um verdadeiro boom turístico, gerado pelas nações mais ricas, que procuravam destinos de "sol e mar" na bacia mediterrânea. A tentativa de diversificação da oferta por parte das operadoras turísticas do Norte da Europa, que se traduziu na busca de estâncias balneares ainda não saturadas e a inauguração do aeroporto de Faro (em 1965), encurtando a distância entre os centros emissores de turistas e as praias algarvias, explicam em parte o impressionante crescimento da procura estrangeira. A evolução da clientela na hotelaria do distrito registou 30.000 dormidas de estrangeiros em 1960, 500.000 em 1967, 1.114 .000 em 1970 e 1.494 .000 em 1972. Simultaneamente, o Algarve foi ganhando adesão enquanto destino de férias dos portugueses, sobretudo depois do 25 de Abril (CAVACO 1969: 237; CAVACO 1980: 260, 265, 270). Dados recentes apontam para 2.220.000 hóspedes estrangeiros e

(1) IELT, Faculdade de Ciências Sociais e Humanas, Universidade Nova de Lisboa, Avenida de Berna, 26 - C, 1069-061 Lisboa; Centro de História, Faculdade de Letras da Universidade de Lisboa, Alameda da Universidade, 1600-214 Lisboa, joana.gaspar.freitas@gmail.com

${ }^{(2)}$ CIMA, Universidade do Algarve, Edifício 7, Campus de Gambelas, 8005-139 Faro, Portugal, jdias@ualg.pt 
930.000 portugueses em 2013 (TURISMO DO ALGARVE 2014:4).

Perante a importância crescente do turismo externo na economia nacional e face aos ganhos obtidos noutros países (Espanha, França e Itália), o governo português apadrinhou o desenvolvimento do sector no Algarve, apoiando as iniciativas privadas. Procurou também dotar a região de um conjunto de instrumentos de gestão e controlo do turismo e da urbanização. Foram, assim, realizados vários estudos e planos com o intuito de analisar a evolução da procura turística, preparar o acolhimento de grande fluxo turístico e acautelar a proteção do património natural. Apesar desta preocupação inicial e planeamento atempado, a descoberta do Algarve pelo turismo de massas significou a transformação irreversível deste território, sobretudo do seu litoral, que enfrenta hoje graves problemas de cariz ambiental: destruição de habitats, poluição e erosão costeira.

O objetivo deste trabalho é analisar, numa perspetiva histórica e ambiental, um período curto de cerca de três décadas (1960-90), de intensa transformação, cujos impactos modificaram e explicam em parte a situação atual da costa algarvia. Assim, são identificados os primeiros planos de urbanização traçados para a região (anos de 1960) e observadas as estratégias de proteção preconizadas para a faixa litoral. Depois apontam-se e explicam-se os fatores políticos, económicos e sociais que determinaram a sua inoperância. Perante diferentes estratégias para a região foram feitas escolhas, umas intencionais, outras ao sabor das circunstâncias, que influenciaram soluções futuras. Pretende-se demonstrar como a incapacidade das autoridades em salvaguardar o património natural da orla costeira perante a afirmação do turismo de massas teve impactes significativos no território e condicionou os planos de proteção posteriores. Por fim, faz-se uma breve análise sobre a gestão do litoral nas últimas décadas. O resultado é uma reflexão sobre o turismo, o ordenamento do território, a proteção de recursos e os impactos na zona costeira, devidamente enquadrados num contexto histórico que explica as motivações dos intervenientes, as grandes linhas políticas que determinam decisões e as reviravoltas que impulsionam mudanças.

\section{MATERIAIS E MÉTODOS}

O método utilizado neste trabalho é o habitualmente usado pelas Ciências Sociais e baseia-se no esquema teoria-documentação-reflexão, ou seja, desenvolvimento de uma ideia, procura de informação para sustentá-la ou refutá-la (através da análise crítica das fontes disponíveis e do recurso a bibliografia sobre o tema), reflexão a partir dos dados obtidos e da comparação com outros casos semelhantes.

A nível dos materiais recorreu-se sobretudo a fontes primárias: estudos e projetos elaborados por organismos públicos, periódicos e testemunhos pessoais que assinalam a transformação da paisagem, e legislação sobre a proteção da orla costeira produzida nas últimas décadas do século XX e no século XXI.

\section{RESULTADOS E DISCUSSÃO}

\section{1. O Estado e a planificação turística do Algarve}

\subsubsection{Os planos para o Algarve}

No início dos anos de 1960, o Algarve estava ainda bastante isolado do mundo quanto a ligações aéreas e marítimas. Não dispunha de aeroporto. Não tinha portos capazes de albergar grandes navios de cruzeiros. Estava mal servido de ligações rodoviárias e ferroviárias com Lisboa, dado o mau traçado das estradas e o estado obsoleto das vias férreas e do material circulante. Quanto à capacidade das instalações hoteleiras, as camas disponíveis eram manifestamente insuficientes (ROSAL 1962:903).

Para converter o Algarve numa região turística, capaz de rivalizar com Espanha, alguns organismos públicos com responsabilidades nas áreas do turismo e do urbanismo foram incumbidos de preparar estudos e planos. O objetivo era estabelecer uma programação que definisse a ordem de prioridade das iniciativas estatais, com vista a adequar a cobertura regional do equipamento turístico a implementar. Assim, surgiram: o Plano de Valorização Turística do Algarve, do Secretariado Nacional de Informação (SNI 1963); o Planeamento Urbanístico da Região do Algarve. Esboceto da Faixa Marginal (MOPC 1964) e o Plano Regional do Algarve, do arquiteto italiano Luigi Dodi (DoDI 1966), encomendados pela Direção Geral dos Serviços de Urbanização; e o Planeamento Turístico do Algarve. Relatório de Base (CT 1966), elaborado pelo Comissariado do Turismo.

Em 1965, por decisão governamental e de acordo com o estipulado no Plano Intercalar de Fomento de 1965-1967 (ASSEMBLEIA DA REPÚBLICA 1965), o Algarve foi considerado região de turismo privilegiada. Em 1972, no IV Plano de Fomento (PCM 1973), foi ratificada esta decisão, destacando-se como zona prioritária de investimento a faixa costeira meridional. O Barrocal e a Serra, bem como o litoral ocidental, ficaram excluídos (pela sua falta de interesse turístico) dos planos de desenvolvimento para a região.

\subsection{O litoral nos planos de desenvolvimento}

Em 1963, no Plano de Valorização Turística do Algarve, o SNI explicava que o planeamento prévio e atempado do desenvolvimento do turismo era determinante para que este se processasse de forma regrada, de modo a não afetar negativamente a economia agrícola e piscatória da região e garan- 
tir a proteção dos seus valores monumentais e naturais (SNI 1963). O arquiteto Dodi, no Esboceto da Faixa Marginal, defendia também esta posição, indicando que a primazia dada à faixa costeira (meridional) se devia à urgência na iniciativa de transformação desta área e à necessidade de se encontrar um ponto de equilíbrio entre o seu desenvolvimento económico e a salvaguarda dos valores arquitetónicos e paisagísticos, que em conjunto com o mar, o sol e as praias, constituíam os elementos privilegiados do turismo regional (DODI et al. 1964:2, 5). Desde o primeiro momento, tornouse evidente, para instituições e técnicos, que era indispensável manter a originalidade do ambiente local. O respeito pela paisagem costeira, que constituía o mais alto valor panorâmico da província, era considerado essencial (Fig. 1); dado que o Algarve só poderia manter a sua posição perante a concorrência internacional, se o desenvolvimento urbanístico que iria processar-se não desfigurasse o que era característico (MOPC 1964:3).

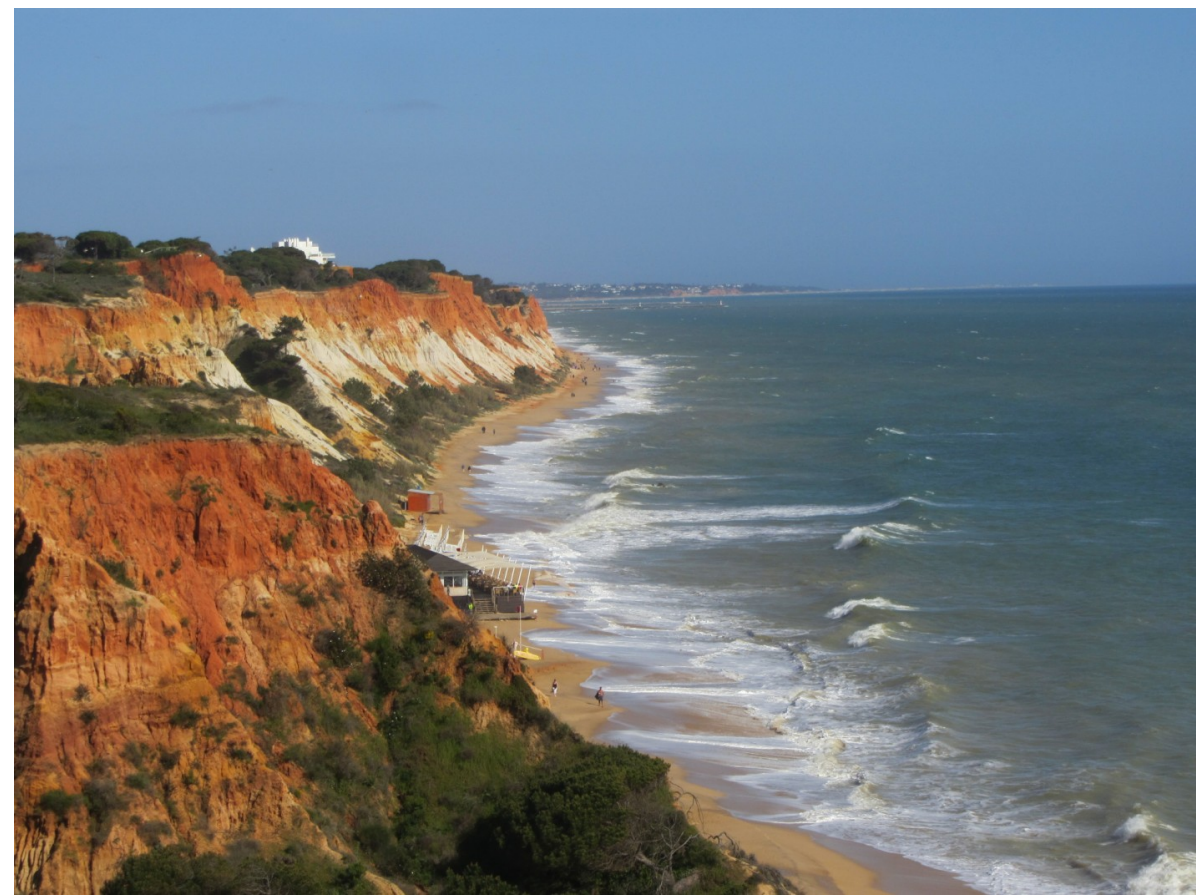

Fig. 1. Praia da Falésia, Olhos d'Água, 2013. Uma das paisagens mais belas da região (Fotografia de Joana Freitas).

Fig. 1. Falésia Beach, located in Olhos d'Água, 2013. One of the most beautiful landscapes of Algarve (Photo by Joana Freitas).

Neste sentido, preconizava-se um planeamento dos recursos turísticos de acordo com o potencial económico regional que garantisse simultaneamente a salvaguarda dos valores naturais sensíveis, considerando que nenhum interesse privado se poderia sobrepor ao interesse público nesta matéria. Deste modo, propunha-se que as praias mais pequenas, correspondentes aos sectores de arribas (no barlavento), deviam, pelas suas características paisagísticas, ficar reservadas a um turismo de qualidade, com baixos índices de ocupação, enquanto os sectores correspondentes a praias de grandes dimensões (no sotavento) se qualificavam para um turismo mais abrangente. Defendia-se um tipo de ocupação caracterizada pela concentração dos alojamentos em poucos, mas bem apetrechados núcleos, deixando o restante espaço livre (DoDI et al. 1964; MOPC 1964). Contudo, já então se admitia que, dada a situação vigente (de invasão de praticamente toda a costa pelas iniciativas priva- das), os trabalhos futuros teriam de se basear num meio-termo, que conciliasse os interesses particulares e os princípios públicos de valorização e estruturação da região (MOPC 1964).

Todo este debate dizia respeito ao litoral meridional. A costa ocidental, pela frieza das suas águas, maior intensidade do vento, maior agitação marítima e inexistência de centros populacionais de apoio às praias, tinha pouca apetência turística, não havendo interesse no potenciamento do crescimento da indústria hoteleira. Pelo contrário, parecia mais vantajoso deixá-la de reserva, tendo em conta futuras necessidades de expansão, ou colocála à disposição do reduzido número de turistas que valorizavam o sossego e isolamento desse território (MOPC 1964).

No Anteplano Regional do Algarve foi feita uma estimativa do potencial turístico da costa, estimando-se a existência de uma extensão de praias de mais de $15 \times 10^{6} \mathrm{~m}^{2}$. Isto representava, 
segundo Dodi (1966), uma capacidade de receção que permitia albergar entre 300.000 a 500.000 banhistas. Para os acolher seria necessário acautelar determinadas situações e planificar o tipo de ocupação destas praias. Assim, para defender valores ambientais e paisagísticos, propugnava-se pela defesa integral de certos trechos entre a Ponta de Sagres e Quarteira, correspondentes à área de arribas, entendida como uma das paisagens de maior beleza da região e com alto grau de vulnerabilidade. Noutros sectores admitia-se a criação de zonas de edificação turística controlada, desde que em posição recuada relativamente à crista das arribas. Em certos núcleos urbanos (como Lagos, Alvor, Portimão, Armação de Pêra, Albufeira, Quarteira, Faro, Olhão, Tavira e Vila Real de S. António) estabelecia-se que todas as novas edificações deviam ser sujeitas a limitações de altura, volume e densidade construtiva, de modo a integrarem-se no espaço preexistente. Previa-se, ainda, a delimitação de espaços destinados à implantação de núcleos turísticos, com possibilidade de construção controlada de hotéis, núcleos residenciais e respetivos equipamentos. Estava incluído neste enquadramento o litoral de Lagos à barra de Alvor, Praia da Rocha, Armação de Pêra, zona oeste de Quarteira, Ilhas de Faro e Tavira, Manta Rota e Monte Gordo.

Ainda em 1966, o SNI, através do Comissariado do Turismo (CT 1966:44) apresentava novo plano, o Planeamento Turístico do Algarve, através do qual propunha uma política geral de desenvolvimento turístico que enquadrasse os estudos urbanísticos que estavam em elaboração pela Direção Geral dos Serviços de Urbanização. O conjunto de normativas de enquadramento dos centros turísticos, divulgado então, ia ao encontro do que já tinha sido explanado no Plano Dodi, revelando a preocupação das autoridades com a proteção da orla costeira face ao proliferar da construção. $\mathrm{O}$ documento do Comissariado do Turismo reafirmava a necessidade de conservar por todos os meios o enquadramento natural dos núcleos urbanos de desenvolvimento turístico situados na faixa marítima e de promover a conservação da paisagem. Para isso era imperativo garantir a concentração da urbanização intensiva em áreas bem delimitadas, de modo a permitir a conservação de largos trechos costeiros com baixas densidades de ocupação; proscrever a implantação sistemática de edifícios sobre a orla marítima; e criar zonas livres, de proteção e valorização paisagística (com uma profundidade mínima de $200 \mathrm{~m}$ a partir do limite máximo da preia-mar), ao longo das praias integradas nas áreas de desenvolvimento prioritário. Com o objetivo de minimizar os impactes da construção, o dito projeto estabelecia ainda o afastamento dos volumes edificados de grande porte para uma segunda linha e impunha limitações à extensão das frentes urbanas contínuas que fossem percetíveis das praias. Fora das zonas de crescimento turístico interessava sobretudo assegurar a integração paisa- gística de edifícios isolados e de pequenos conjuntos imobiliários nos terrenos confinantes com o mar. Assim, preconizava-se para estas áreas: a fixação de uma densidade média de ocupação na ordem dos 10 hab./ha numa faixa com uma profundidade de cerca de $700 \mathrm{~m}$ ao longo da costa; e a definição de uma faixa mais restrita, na ordem dos $200 \mathrm{~m}$, para a qual se estipulavam com precisão as características dos edifícios a admitir.

\subsection{Análise dos planos}

A coordenação de esforços no sentido da harmonização do planeamento turístico e urbanístico do Algarve resultou na consolidação (teórica) da posição estratégica de algumas importantes instituições do regime em relação àquela região. Estratégia que se baseava na qualidade (ao contrário do que havia sido feito em Espanha pelo governo franquista) através da compatibilização de uma política de aproveitamento dos recursos turísticos com a preservação dos valores naturais e culturais da província. Esta afirmação pode parecer ousada dada a influência do modelo espanhol no desenvolvimento do turismo algarvio e se for tido em conta aquilo que foi concretizado posteriormente. No entanto, a análise dos planos de 1963-67 mostra a existência de uma visão que privilegiava a qualidade em detrimento da quantidade e que salvaguardava os valores paisagísticos através do controle do crescimento urbano. Aqueles valores eram entendidos como preponderantes enquanto atração turística e mais-valias relevantes face à concorrência de outras áreas mediterrâneas com equipamentos de maior potencial, mas saturadas e descaracterizadas por excessivo desenvolvimento e rarefação dos elementos naturais.

Assim, deu-se particular relevo à necessidade de aplicar medidas de proteção, como a delimitação de áreas non aedificandi e a promoção de iniciativas para a conservação e valorização de paisagens. Consignou-se, ainda, a existência de uma "zona de interesse turístico", constituída por uma faixa contínua ao longo do litoral, com uma largura média de cerca de $700 \mathrm{~m}$, sobre a qual recaía a atenção das iniciativas privadas e que, por isso, exigia a intervenção do Estado para impor regras de utilização. Previa-se, também, a delimitação de "áreas de desenvolvimento turístico prioritário", nas quais seriam aplicadas medidas de promoção especiais destinadas a incentivar a concretização de espaços turísticos bem apetrechados e de elevada qualidade. Esta política estatal de concentração de meios visava servir de travão à dispersão das iniciativas privadas, tendo em vista o controlo efetivo das transformações do território e a redução dos encargos públicos com a instalação de infraestruturas e serviços básicos (CT 1966).

A atualidade destas preocupações (turísticas, urbanísticas e ambientais) é notável, não tendo sido 
por falta de conhecimento atempado da realidade e da perspetiva da sua evolução que se terá chegado à situação de degradação que se vive nalguns trechos deste litoral. Contudo, por vicissitudes várias (políticas, económicas e sociais), grande parte destas medidas só viria a ser implantada nos anos de 1990 , com a aplicação do Plano Regional de Ordenamento do Território do Algarve e do Plano Regional de Turismo do Algarve (SOARES 1997:94, 96, 179).

\section{TURISMO DE MASSAS VERSUS PLANOS DE ORDENAMENTO}

\subsection{A afirmação do turismo de massas}

O crescimento da procura turística do Algarve a partir de $1960 \mathrm{fez}$ espoletar o problema da falta de alojamentos e deu início à corrida para a compra de terrenos em locais de interesse paisagístico, sobretudo no litoral. O exemplo de Espanha, que faturava milhões com a exploração das suas estâncias balneares, assim como a importância económica do turismo para o equilíbrio das finanças do Estado português e o aumento do interesse dos operadores turísticos internacionais pelo sul do país tiveram efeito catalisador no que toca à construção de estruturas de acolhimento para o número crescente de estrangeiros que buscavam o sol algarvio.

Nos anos de 1970-80, depois de um abrandamento imposto pelas vicissitudes políticas (o 25 de Abril de 1974), a procura externa de Portugal enquanto local de veraneio progrediu a ritmo acelerado (BRITO 2005:68). Em 1977, ano de recuperação do turismo, a imprensa noticiava: «Hotéis do Algarve estarão cheios no próximo verão» (EXPRESSO 23-12-1977:12). Impulsionado pela necessidade de atender às solicitações, o ramo do imobiliário cresceu espantosamente em pouco mais de duas décadas, invadindo os terrenos ainda livres ou edificando em altura de forma a compensar a subida de valor das propriedades (Fig. 2 e 3 ).

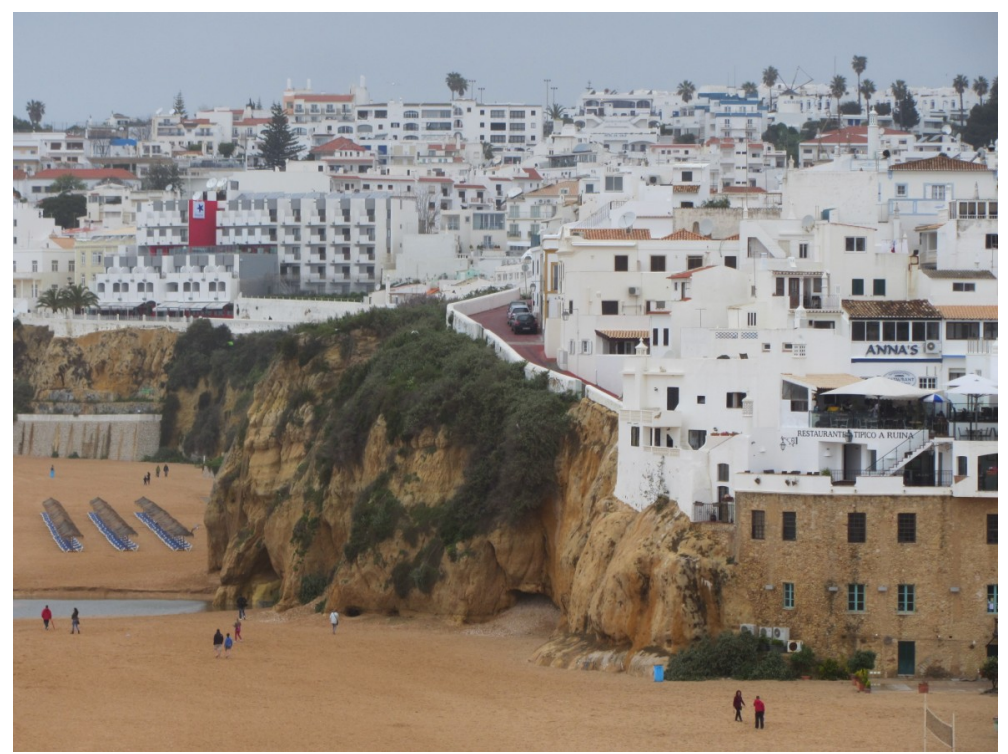

Fig. 2. Praia dos Pescadores em Albufeira, 2013. Uma das áreas algarvias mais afetadas pelo turismo de massas (Fotografia de Joana Freitas).

Fig. 2. Fishermen Beach in Albufeira, 2013. One of the most affected areas, in Algarve, by mass tourism (Photo by Joana Freitas).

\subsection{Fatores que determinaram a inoperân- cia dos planos}

As primeiras críticas ao crescimento anárquico do sector imobiliário fizeram-se sentir ainda na década de 1960. Em virtude das facilidades concedidas pelo Estado à iniciativa privada (decorrentes do reconhecimento de utilidade pública do turismo), assistiu-se ao proliferar de uma construção desregrada, marcada pela pressão dos interesses e das influências. Entendia-se já então que a responsabilidade cabia ao Estado e às câmaras municipais. Se o primeiro era responsável pela falta de um estatuto jurídico-económico que definisse as situações criadas pelo turismo em relação à utiliza- ção dos terrenos, as segundas eram acusadas de não obedecer à legislação em vigor em matéria de urbanismo, pois para atraírem e fixarem no seu concelho investimentos, davam demasiadas facilidades aos empresários e pactuavam com abusos (RosAl 1967:1866-1867). Nos anos seguintes, com a expansão do turismo de massas, a questão urbanística conheceu novo impulso, aceitando-se de forma geral que o incumprimento das normas era o preço a pagar pelo progresso económico e material que se pretendia implementar (Fig. 3).

O 25 de Abril e o Período Revolucionário em Curso (PREC), com toda a instabilidade política associada que se prolongou por alguns anos, repre- 
sentaram uma janela de oportunidade para muitos empreendimentos, sendo esta a época «da primeira grande vaga de construção imobiliária no Algarve, período em que dezenas de unidades hoteleiras e aldeamentos turísticos foram autorizados sem olhar à sua localização, enquadramento paisagístico ou sequer à possibilidade de serem abastecidos de água potável e terem para onde descarregar os seus esgotos» (FERNANDES 1985:21-22). Para certos autarcas e empresários o modelo a seguir provinha de Espanha, consubstanciando-se no paradigma de Torremolinos (EXPRESSO. ESPECIAL FÉRIAS 80 1980; FERNANDES 1982:37-41; 1984:7).

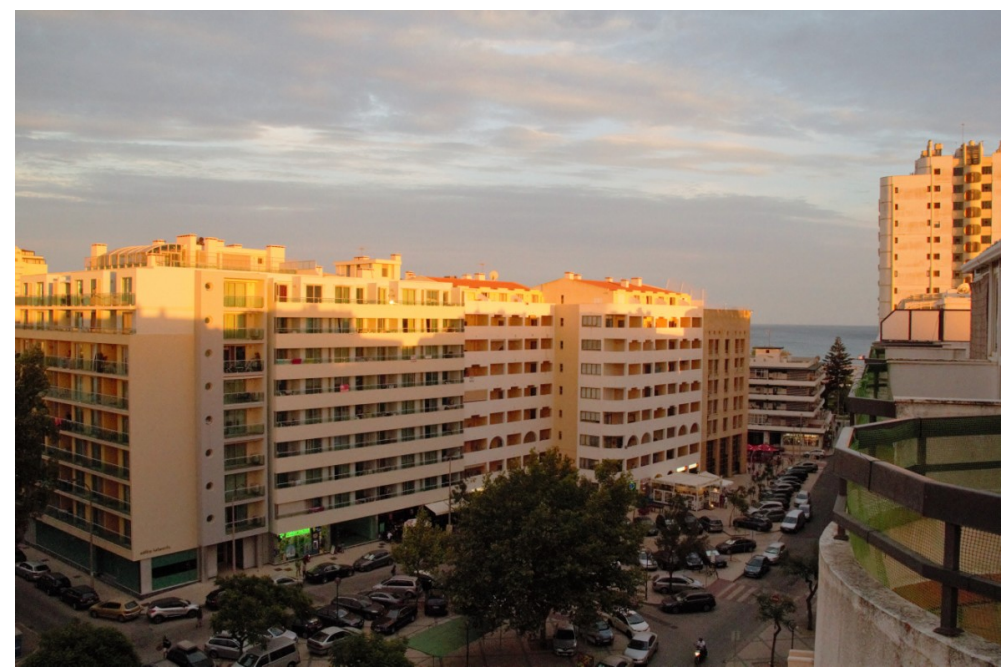

Fig. 3. Monte Gordo, 2015. Outrora uma praia de pequenas casinhas alinhadas junto ao areal, Monte Gordo converteu-se num aglomerado de edifícios de grande volumetria, sem qualquer interesse arquitetónico (Fotografia de Joana Freitas).

Fig. 3. Monte Gordo, 2015. In the past this was a village with nice small houses lined up near the beach. In just two or three decades, Monte Gordo was transformed into a city with big ugly buildings without any special architectonic features (Photo by Joana Freitas).

\subsection{Porque falharam os planos? Uma reflexão}

Na década de 1960, alguns serviços públicos empenharam-se na definição de planos turísticos e de urbanização para o Algarve, decididos a organizar e controlar o processo de crescimento e implantação territorial daquela indústria, a fim de evitar os excessos evidenciados em países que se haviam lançado antes na corrida pelos proveitos do turismo. Porém, cedo se notou a existência de forte desfasamento entre o processo de planeamento, organizado em moldes essencialmente teóricos, e a realidade do desenvolvimento turístico. Em 1969, os técnicos responsáveis pela elaboração do Plano Regional do Algarve chamavam a atenção para a circunstância deste poder vir a converter-se em pura abstração, ficando a realidade desprovida de todo o apoio operacional que o dito plano visava oferecer (ATAS DAS SESSÕES DA COMISSÃO CONSULTIVA DE URBANIZAÇÃO DO DISTRITO DE FARO 1969:1). A não aprovação deste e de outros instrumentos de planeamento refletiu a incapacidade governativa para ultrapassar as dificuldades inerentes à materialização dos planos, cujas normativas, não sendo suscetíveis de mentalizar e interessar as entidades e as populações no sentido de estabelecer um quadro de referência permanente, corriam o risco de ser postas em causa e de ficarem vazias de sentido em termos de aplicação prática. $\mathrm{O}$ próprio Estado se encontrava na situação delicada de pretender uma política de cautela e protecionismo em relação ao turismo e, em simultâneo pactuar (e até promover) com as iniciativas privadas para o seu desenvolvimento, dada a necessidade premente de obtenção de divisas, pois convém ter presente que o país estava a braços com uma guerra colonial em várias frentes. A inauguração do aeroporto de Faro, que propiciou a vinda de número crescente de turistas, para os quais não havia as infraestruturas necessárias, e a transformação do Algarve no Eldorado português (SANTOS 1965: 178) fizeram crer que o turismo seria a panaceia de todos os problemas da região (e quem sabe do país). Além disso, a política de incentivos ao aumento dos meios de receção, desenvolvida nas décadas de 1960-70 e princípios de 1980, foi guindada pela convicção de que este crescimento e suas repercussões territoriais seriam enquadradas e minimizadas por planos de ordenamento e medidas específicas de salvaguarda dos valores patrimoniais e naturais. Mas, estes acabaram por não ser concretizados nesses tempos (e nalguns casos nem no atual) (SOARES 1997:99-100). Isto significa que, embora tenha sido sentida desde logo a necessidade de articular o turismo e o ordenamento do território de forma a promover um 
desenvolvimento harmonioso e integrado para a região, o que se verificou foi o incremento substancial do sector turístico em detrimento das preocupações com o seu impacto sobre o espaço de implantação, considerando-se que, dada a importância económica daquele, não se podia (ou devia) colocar obstáculos ao seu crescimento. Na ausência de estratégias globais em matéria de planeamento do turismo, a procura assumiu-se como motor do crescimento e ordenamento da oferta turística, que proliferou com base em esforços descoordenados e sujeitos aos interesses da iniciativa privada. Desta forma, inviabilizou-se parcialmente a operacionalidade futura dos instrumentos de planificação, pois estes, quando finalmente implementados na década de 1990, viram-se obrigados a ratificar soluções já existentes e a pactuar com direitos, entretanto adquiridos (GonÇALVES1996: 187). Perante a agressividade do investimento imobiliário na orla costeira e a falha das formas de controlo público, assistiu-se à ocupação dos espaços litorais segundo os moldes das «urbanizações (ou suburbanizações) metropolitanas que caracterizam o mau crescimento e renovação urbana do último meio século. (...). Nunca arquitetos e engenheiros projetaram tanto como nos Algarves, nestas três décadas, mas também nunca se deve ter acumulado tanto disparate ou tantos golpes baixos urbanísticos-arquitetónicos, como nessa galinha de ovos de ouro do betão» (PORTAS 1991:91).

\section{IMPACTO DO TURISMO SOBRE O LITORAL ALGARVIO}

\subsection{Consequências do crescimento urbano}

No início de 1980, começaram a surgir os primeiros sinais de alerta para a situação que se vivia no sul. Passando de território ignorado a espaço apetecível e prolificamente visitado em menos de trinta anos, o Algarve foi deixado à iniciativa privada que, à custa do sol e das praias, explorou uma próspera indústria turística, usufruindo dos proveitos e lucros imediatos sem pensar nas consequências futuras do crescimento sobredimensionado para as capacidades naturais e estruturais da região. Assim, ao fim de pouco tempo começaram a avolumar-se os problemas.

O Algarve enfermava de falta de estruturas de saneamento básico, como água, esgotos e seu tratamento, comprometendo as condições de vida da população. Durante o verão, época de maior afluência turística, a água escasseava nas torneiras e a pouca que corria era, muitas vezes, salobra. Por seu turno, os esgotos eram lançados nos rios e nas praias, inquinando as águas marítimas das principais (e mais concorridas) estações balneares. Em Albufeira, por exemplo, os detritos da vila corriam para o mar através de um cano existente na praia e todos os anos numerosos turistas regressavam a casa com disenteria e outras doenças. Um pouco por todo o litoral proliferava a urbanização selvagem, dispersa e sem dimensão: os núcleos urbanos cresciam a ritmo desmesurado, recorrendo a construção barata e de má qualidade, que apostava sobretudo em grandes volumetrias (na horizontal e vertical), sem qualquer respeito pelas características das edificações pré-existentes (Fig. 3 e 4). As próprias unidades hoteleiras eram erguidas sem as infraestruturas mínimas, sem estradas de acesso e, por vezes, clandestinamente, como sucedeu com o hotel de dez andares de Monte Gordo (EXPRESSO Revista 31-05-1980:6; EXPRESSO 30-08-1980:14; FERNANDES 1982:37-41). No sotavento, onde as arribas davam lugar a uma costa baixa e arenosa, os aldeamentos e hotéis eram substituídos por parques de campismo e habitações clandestinas (EXPRESSO Revista 10-09-1983:17).

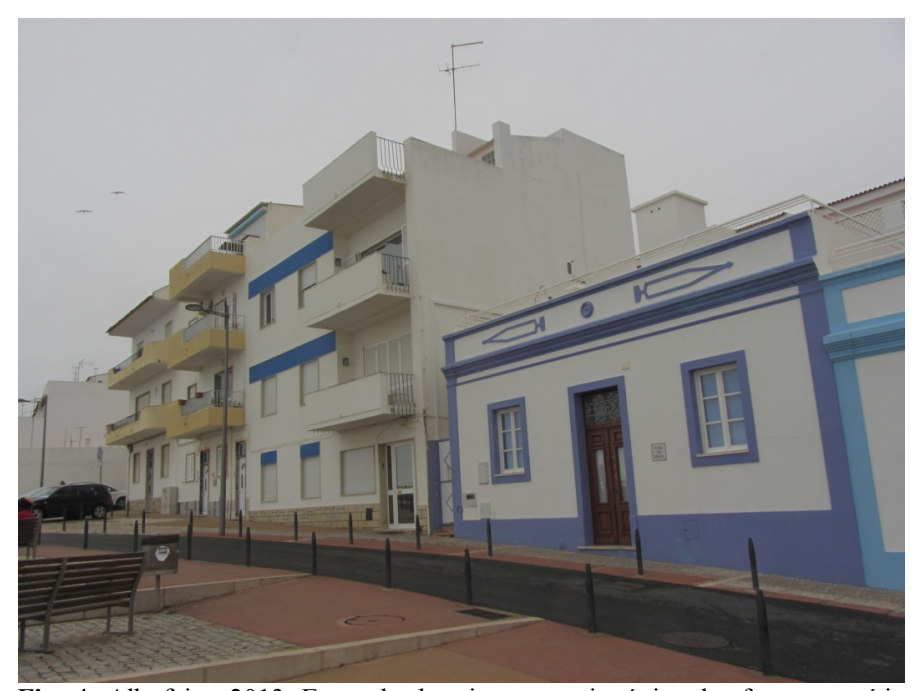

Fig. 4. Albufeira, 2013. Exemplo da mistura arquitetónica das frentes marítimas. Novas construções contrastam com as casas típicas da região (Fotografia de Joana Freitas)

Fig. 4. Albufeira, 2013. Example of mixed architectonic features in the houses near the seashore. The new buildings stand next to the old typical homes of the region. 


\subsection{Erosão costeira: aumento dos fatores de risco}

O registo histórico e os estudos científicos mais recentes apontam para um aumento significativo dos fenómenos de erosão costeira a partir de meados do século XX. Os dados existentes não só confirmam a continuidade dos casos anteriores, como assinalam o alastramento destes eventos a áreas antes não afetadas, ao mesmo tempo que registam a intensificação da gravidade do problema, em virtude da maior ocupação da orla marítima (ANDRADE et al. 1989:68; FREITAS 2010). Ainda que a erosão seja um fenómeno natural inerente ao funcionamento dos sistemas costeiros e à atual tendência para a migração da linha de costa em direção ao continente (carácter transgressivo) (DIAS 2004:2), existe relação direta entre determinadas atividades humanas e as rápidas alterações que se fazem sentir no litoral. Assim, se os processos erosivos antecederam a ocupação e transformação intensiva do uso do solo na orla marítima, como atestam os relatos do século XIX (FREITAS 2010), foi com a urbanização progressiva do litoral e a redução do abastecimento sedimentar devido à construção de barragens, marinas e esporões, que os ditos mecanismos se tornaram mais acutilantes do ponto de vista do recuo da linha de costa e dos prejuízos causados.

Nas zonas mais críticas (Albufeira, Armação de Pêra, Quarteira, Vale de Lobo e Ilha de Faro), nas últimas décadas têm-se assistido à ruína de infraestruturas erguidas sobre as arribas, como o Forte Novo ou algumas moradias de Vale de Lobo, ou à invasão pelas águas e/ou areias de casas e arruamentos, como acontece na Ilha de Faro durante marés de sizígia. A manter-se a atual tendência de evolução da linha de costa, aumentarão necessariamente as situações de risco induzidas pela instabilidade das arribas e pelos galgamentos oceânicos, tanto mais que a importância do fenómeno turístico nesta região e a atratividade socioeconómica das frentes marítimas fazem com que seja elevada (e potencialmente crescente) a pressão urbanística e populacional sobre este litoral (Fig. 5). Daí a urgência sentida nos últimos anos de se fixarem regras quanto à ocupação e utilização do solo nas faixas costeiras, tendo em conta a salvaguarda da segurança de pessoas e bens, a conservação e perdurabilidade de infraestruturas e edificações, a preservação da paisagem natural e a minimização das situações de perigo (MARQUES 1997:433).

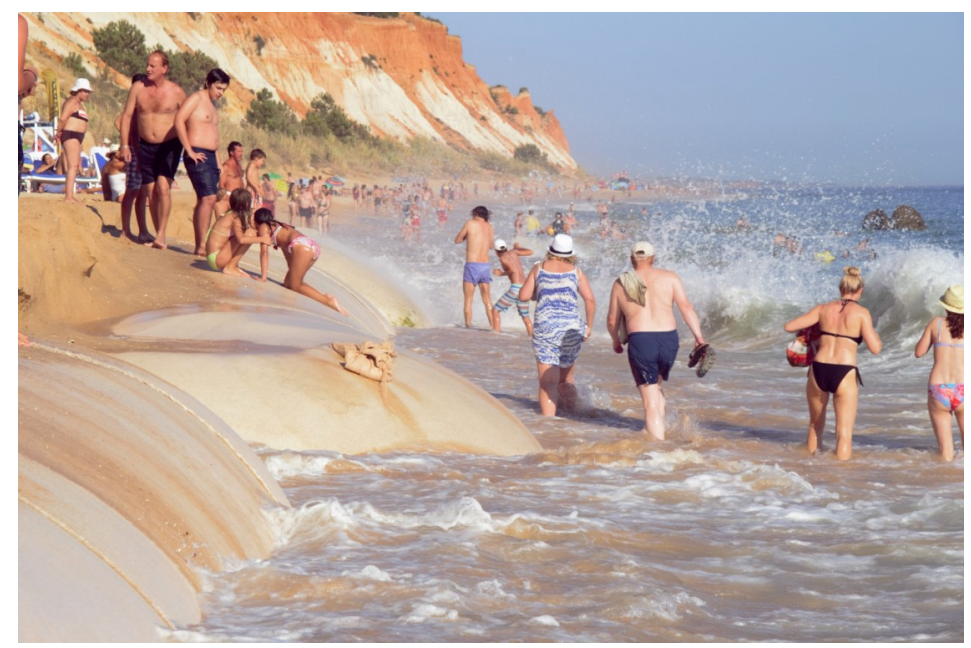

Fig. 5. Praia da Falésia, Olhos d'Água, 2013. Falta de areia a afetar a praia do resort de luxo Pine Cliffs. A solução encontrada (sacos em geotêxtil) revelou efeitos inesperados para os frequentadores da praia (Fotografia de Joana Freitas).

Fig. 5. Falésia Beach, in Olhos d' Água, 2013. The lack of sand is affecting the beach of Pine Cliffs luxury resort. The solution (geotextile bags with sand) caused unintended sideeffects (Photo by Joana Freitas).

\section{GESTÃO DA ORLA COSTEIRA: PROTEÇÃO VERSUS APROVEITAMENTO}

\subsection{Os planos da década de 1990}

Na década de 1990, começaram a ser aprovados os Planos de Ordenamento da Orla Costeira (POOC), cujo objetivo principal é a compatibilização entre a utilização turística, sobretudo o uso balnear, e as características, sensibilidade e capacidade de carga do litoral. Tarefa de grande comple- xidade, uma vez que a área de aplicação desta figura de ordenamento (entre a batimétrica dos $30 \mathrm{~m}$ e uma faixa cuja largura não excede os $500 \mathrm{~m}$ a partir da linha que limita a margem das águas do mar) (DIÁRIO DA REPÚBLICA 1993:4626) é muito vulnerável em termos ecológicos e extremamente atrativa do ponto de vista socioeconómico, o que a converte num espaço de conflitos, pela dificuldade em gerir usos incompatíveis entre si. 
$\mathrm{Na}$ prática, o litoral algarvio foi dividido e sujeito a três diferentes planos: Sines-Burgau, Burgau-Vilamoura e Vilamoura-V.R. de Santo António. Estes planos tiveram de se posicionar face às pré-existências e aos "direitos adquiridos" de utilização do solo. Em 1999, data de aprovação do POOC Burgau-Vilamoura (DIÁRIO DA REPÚBLICA 1999:2232-2257), já esta zona estava densamente urbanizada, tendo-se optado por pactuar com a situação instalada, sancionando os desmandos urbanísticos dos anos de 1970-80. Depois, embora a legislação tenha proibido novas construções e a ampliação em volume e altura das já existentes, para travar a sua expansão e minimizar o seu impacto, na prática o que se verificou foi o recurso (frequente) a medidas de exceção, como os "Projetos de Interesse Nacional" (PIN), que promovem a celeridade dos procedimentos necessários à aprovação dos projetos e permitem ultrapassar as limitações impostas nos planos de ordenamento do território e de reserva agrícola e ambiental (EXPRESSO 25-08-2006). Em 2009 havia 12 PINs (em diferentes fases) no Algarve, que representavam mais 14 mil camas na região (BARLAVENTO 2803-2009). Este é um exemplo de como a pressão dos promotores turísticos e o valor dos investimentos envolvidos justificam muitas vezes a suspensão dos planos de ordenamento ou a sua alteração, a fim de permitir a instalação ou ampliação de novas unidades hoteleiras ou infraestruturas de recreio, em nome do desenvolvimento regional, e à custa do aumento da pressão antrópica sobre o litoral.

Os POOC, que visavam ser instrumentos de planeamento global da faixa marítima a nível nacional, promovendo um conjunto de ações que permitissem o aumento do conhecimento sobre o litoral; a contenção da expansão urbana em zonas de risco e de maior sensibilidade ecológica; a requalificação de praias; e a identificação das necessidades de intervenção de defesa costeira em zonas críticas e instáveis, têm-se revelado manifestamente incapazes de pôr em prática as medidas preconizadas, por razões de ordem vária. Primeiro, a necessidade da sua aprovação pelos poderes centrais e autárquicos, parques naturais, associações e instituições de carácter diverso (pescadores, indústria, turismo), com interesses frequentemente antagónicos, exige situações de compromisso, nas quais a preservação do litoral fica quase sempre a perder. Segundo, havendo uma pluralidade de entidades responsáveis pela sua aplicação e sobreposição de poderes, verifica-se diluição das capacidades mandatórias de cada uma e ausência prática de resultados. Com efeito, até recentemente, os POOCs eram da responsabilidade da DirecçãoGeral de Portos, do Instituto da Água e do Instituto de Conservação da Natureza, mas muitos outros organismos são intervenientes, como as Direções Gerais da Marinha, das Pescas e do Turismo, as Comissões de Coordenação e Desenvolvimento
Regional e os vários municípios que confinam com a orla costeira. Terceiro, a divisão do litoral (que constitui um todo homogéneo) em diferentes partes, submetidas a regulamentos distintos, «cria descontinuidades indesejáveis na gestão de um sistema biofísico coeso e indivisível, para além de gerar problemas difíceis de resolver no quadro legislativo atual, no que respeita à compatibilização de prioridades e à coerência de procedimentos» (CNADS 2001:7). Com efeito, as instituições envolvidas têm perspetivas e interesses muito diversos, dificilmente compatibilizáveis, sobretudo quanto aos valores económicos/turísticos versus salvaguarda do património natural. Quarto, a necessidade de harmonizar os POOC com planos já existentes (Planos Regionais de Ordenamento do Território, Planos Diretores Municipais e outros) torna extraordinariamente problemática a tarefa de gerir as medidas de proteção/contenção de riscos preconizadas para a orla costeira com os «direitos adquiridos a nível de exploração e urbanização» (CNADS 2001:8) dessa zona. Por fim, dada a dificuldade de compatibilizar os interesses e a forte pressão dos lobbies dos grandes grupos económicos ou das próprias autarquias, verifica-se clara falta de vontade política para sustentar estratégias ambientalmente pertinentes, como pôr fim à construção de novos empreendimentos em áreas naturais vulneráveis, a concretização de expropriações/ demolições e a aplicação efetiva das opções de retirada programada.

Em 2007, no balanço feito à atuação do POOC Burgau-Vilamoura, concluiu-se que este apresentava «alguma derrapagem no tempo em termos de execução», revelando um nível médio de execução física, sendo que o tipo de intervenção mais praticado era o da "requalificação de praias", ou seja, a construção de parques de estacionamento e apoios de praia, a medida mais (ou a única) consensual a nível da aplicação do dito regulamento (MAOTDR 2007:105, 110). O caso das habitações clandestinas que enxameiam as ilhas-barreira da Ria Formosa é o melhor exemplo das dificuldades de aplicação das medidas de intervenção propostas no POOC, já que a demolição daquelas (solução mais acertada para o problema da erosão costeira ali existente) foi consecutivamente travada pela oposição das autarquias. Finalmente, em 2015, a Sociedade Polis Ria Formosa pôs em prática o que estava previsto há dezenas de anos. Em janeiro de 2016 ia a meio o programa de demolições de casas de férias nas ilhas-barreira - de um conjunto de 750 já tinham sido derrubadas 370 -, mas, entretanto a Câmara de Olhão e os proprietários das casas recorreram aos tribunais para parar o processo (REVEZ 2016ab).

Nas últimas décadas, essencialmente, o que se fez foi a adoção de medidas de contenção, tentando os novos planos de ordenamento conciliar situações de facto com salvaguarda de valores 
ambientais e sociais, embora, muitas vezes, essas intenções fiquem apenas como no domínio de jure, não se traduzindo realmente em ações de facto.

\subsection{Os primeiros anos do século XXI - um balanço}

Desde os anos de 1980, tem sido bastante prolixa a emissão de diplomas legais destinados à proteção do ambiente e à regulamentação dos usos do solo, sendo alguns especificamente para a faixa litoral. A título de exemplo mencionam-se o Domínio Público Hídrico (1971), a Reserva Ecológica Nacional (1983), os POOCs (1993), a Estratégia Nacional para a Conservação da Natureza (2001), a Lei da Água (2005), o Plano de Ação para o Litoral 2007-2013 (2007), a Estratégia Nacional para a Gestão Integrada da Zona Costeira (2009) e o Plano de Ação e Valorização do Litoral 2012-2015 (2012). Não tem sido, pois, a falta de legislação ou de estudos a explicação para o desfasamento entre as intenções e a prática.

$\mathrm{O}$ texto da Estratégia Nacional para a Gestão Integrada da Zona Costeira (ENGIZC), de 2009, identifica com clareza quais são os problemas relativos à governação deste espaço. Ali se reconhece que a par da intensa concentração demográfica e económica no litoral, da ocupação desordenada e caótica do território (muitas vezes em zonas de risco) e da sobre-exploração dos recursos se verifica a desadequação do modelo de governação para assegurar uma resposta adequada aos novos paradigma e à necessidade de conciliar interesses em favor do desenvolvimento sustentável. Mais, menciona-se a existência de um quadro institucional complexo, a multiplicidade de políticas sectoriais, a diversidade de instrumentos (e instituições) com incidência na zona costeira e a falta de dados por insuficiente monotorização (DIÁRIO DA REPÚBLICA 2009: 6059, 6065). Questões, já assinaladas no relatório do CNADS (2001) a propósito dos POOCs, que a ENGIZC se propõe solucionar através da articulação das dinâmicas socioeconómicas e ecológicas, da gestão de competências e da cooperação público-privada. As metas a atingir com esta estratégia são a conservação e valorização dos recursos naturais paisagísticos e culturais, a prevenção e gestão de situações de risco e a promoção do desenvolvimento sustentável de atividades geradoras de riqueza (DIÁRIO DA REPÚBLICA 2009: 6069). Na ENGIZC, tal como nos projetos dos anos de 1960 e noutros posteriores, os problemas estão identificados e há propostas para a sua resolução. Mas até que ponto estas soluções foram aplicadas ou mostraram ser eficientes?

O relatório do Grupo de Trabalho para o Litoral, divulgado em dezembro de 2014, põe o "dedo na ferida" quanto à situação presente da gestão da orla costeira. «A legislação relativa ao litoral em Portugal [tem] atualmente uma complexidade porventura excessiva». Esta complexidade dificulta a sua aplicação e fiscalização e propicia conflitos de interpretação, que levam com frequência ao recurso aos tribunais (SANTOS et al. 2014: 57, 68). Muitos dos programas desenvolvidos nos últimos anos - como o Litoral (1998) e o Finisterra (2003) - tiveram um nível de implementação que ficou aquém dos objetivos traçados, embora nunca se tenha feito uma avaliação dos resultados (SANTOS et al. 2014: 77-78). Quanto ao modelo de governança, o Grupo de Trabalho entende que a gestão integrada das zonas costeiras pressupõe liderança política, financiamento adequado, articulação e cooperação institucional, mecanismos de comunicação eficazes e participação. Nos últimos vinte anos, contudo, foram frequentes as alterações nos modelos institucionais adotados, porque dependentes das orgânicas de vários governos, estabelecendo assim problemas de coordenação, partilha de informação, falhas nas redes de monotorização e incapacidade de constituir equipas com a experiência adequada. As estratégias apontadas na ENGIZC parecem ter, segundo o Grupo de Trabalho, as potencialidades necessárias, mas o modelo ali defendido está por aplicar (SANTOS et al. 2014: 103).

Estas (e outras) deficiências relativas à gestão do litoral tinham sido já assinaladas pelo Projeto CHANGE, coordenado por Luísa Schmidt (SOARES 2014). Apesar da visão harmónica e da vontade expressa de promover um desenvolvimento sustentável de valorização de recursos, articulação de dinâmicas, interesses e atores, os modelos institucionais adotados têm-se mostrado dispersos e incoerentes no que toca à gestão da orla costeira, sobretudo, face à pressão dos dois principais motores da economia portuguesa: o turismo e a construção civil (SCHMIDT et al. 2012: 25 e 36). Esta situação afeta não só as decisões políticas tomadas pelos governos no que respeito ao ordenamento do território, mas também a sua eficácia, a nível autárquico, dada a articulação entre o financiamento das câmaras e os negócios do imobiliário (SCHMIDT 2009). Deste ponto de vista, verifica-se que entre os planos de 1960 (e as razões que justificaram a sua inoperância) e os projetos mais recentes (e a dificuldade na sua aplicação) não há grandes diferenças. As intenções de proteção do litoral algarvio encontram-se hoje, como então (ou desde então) sujeitas a fortes interesses que colocam sérias dificuldades à sua concretização. Mas, significa isto que nada mudou em todos estes anos e que é de todo impossível impedir a massificação do litoral?

Não, houve mudanças. O panorama acima aludido ocorre principalmente na zona costeira central do Algarve. As partes oriental e, principalmente, ocidental da região resistiram bastante à especulação imobiliária desenfreada. Na parte ocidental, a costa essencialmente rochosa, com pequenas praias de bolso, e as águas mais frias tinham menor apetência para o desenvolvimento do turis- 
mo de massas, o que foi reforçado pela criação, em 1988, da Área de Paisagem Protegida do Sudoeste Alentejano e Costa Vicentina, convertida, em 1995, em Parque Natural do Sudoeste Alentejano e Costa Vicentina. Também na parte oriental, a criação, em 1978, da Reserva Natural da Ria Formosa, convertida em Parque Natural da Ria Formosa em 1987, impediu que se processassem ocupações turísticas de grande envergadura. $\mathrm{O}$ mesmo se verificou, mais a oriente, junto à fronteira com Espanha, com a Reserva Natural do Sapal de Castro Marim e Vila Real de Santo António, criada em 1975, e com o Parque Natural do Vale do Guadiana, instituído em 1995. Nestes casos, o estatuto de proteção ambiental, além de proteger os valores ecossistémicos e culturais das áreas assim classificadas, constitui, também, mecanismo eficaz para evitar o turismo de massas, viabilizando o desenvolvimento de outros nichos de turismo, como o ambiental.

Da mesma forma, os POOCS, apesar de todas as suas fragilidades, tiveram um contributo importante para o estabelecimento de regras de uso e ocupação das zonas costeiras. O Grupo de Trabalho do Litoral destaca o seu papel na valorização das áreas de domínio hídrico e sua utilização e fruição públicas. Bem como, a sua relevância na consciencialização dos gestores do território, a nível nacional e local, e dos cidadãos para um espaço muito pressionado, dinâmico e vulnerável, com grandes apetências paisagísticas, económicas, sociais e culturais (SANTOS et al. 2014:63). Nestas cinco décadas, entre muitas outras mudanças, ganhou-se uma nova consciência face aos problemas ambientais e a sociedade tornou-se mais exigente e interveniente - através da imprensa e das associações ambientais - no que respeita à preservação dos valores da natureza e das paisagens. A generalização das discussões em torno das repercussões das alterações climáticas veio dar mais peso ao fator "risco", que já contava (pelo menos para cientistas, técnicos e decisores) na gestão do litoral, ao qual a opinião pública está agora mais atenta.

Há ainda que mencionar os impactos da crise económica que atingiu Portugal e teve consequências pesadas no que toca aos sectores do turismo e do imobiliário no Algarve. A construção civil, que tem diminuído nos últimos dez anos, registou o seu nível mais baixo em 2014 (IDEALISTA NEWs 10-03 -2015; Villalobos \& ReVEZ, 09-12-2015). A crise travou muitos dos projetos imobiliários em curso, incluindo alguns PINs. Isto parece ter gerado, pelo menos em algumas áreas, uma vontade de pensar no que mais convinha à região: «cimentar por cimentar já se provou que é mau». O Algarve, escrevia o Barlavento, deve ser palco de uma profunda reflexão para saber se a trave mestra do futuro passa pelo imobiliário ou por vetores como o ambiente, a cultura, a história, a saúde e outros (BARLAVENTO, 10-04-2009).

Para terminar, as boas normas a observar na ocupação, uso e transformação da zona costeira são conhecidas há muito (ex. o DL n. ${ }^{\circ} 302 / 90,22$ setembro). As soluções possíveis tendo em conta as características do litoral e a situação da ocupação humana ali existente são conhecidas há décadas. As principais recomendações do Grupo Trabalho tendo em vista uma gestão mais eficaz do litoral - como a criação de uma estrutura interministerial com responsabilidades na articulação da coordenação entre as diferentes instituições, a realização de obras pesadas de engenharia em função do seu real custo-benefício, a relocalização de aglomerados e populações em risco, a reposição do equilíbrio sedimentar através da alimentação artificial e do recurso à transposição de sedimentos não são novas, tendo sido já enunciadas antes (ex. DIAS 1993). O que significa que pelo menos desde a década de 1990 (senão antes) se conhecem as melhores estratégias para lidar com os problemas do litoral português. Porque não foram então implementadas? Pelas razões já descritas e outras: interesses divergentes, falta de financiamento, passividade e falta de vontade política, oposição das populações, fragmentação de competências, etc. Assim, mais do que a nomeação de novos grupos de trabalho e o gizar de planos para o litoral, urge definir uma estratégia única, que se mantenha coerente e independente das mudanças governamentais, pondo em prática as soluções há muito estabelecidas e colocando o bem comum acima dos interesses privados.

\section{CONCLUSÃO}

$\mathrm{O}$ isolamento do Algarve relativamente ao restante território nacional até à segunda metade do século XX, o início tardio da ocupação intensiva da faixa costeira e o facto de constituir hoje a principal região turística portuguesa fazem deste espaço um caso especial. $\mathrm{O}$ desenvolvimento urbanístico processou-se em pouco mais de três décadas, graças ao empenho das autoridades e dos investidores privados em transformá-lo num destino turístico alternativo a Espanha. As tentativas de minimização dos impactos do turismo sobre o território e, mais especificamente, sobre a orla costeira, verificaram-se ainda na década de 1960, através da realização de estudos e planos. Já então havia consciência da necessidade de delimitar áreas non aedificandi e criar zonas de crescimento urbano controlado, mas a maioria destes projetos nunca saiu do papel. Razões várias de ordem política (a mudança de regime e a instabilidade que se lhe seguiu), económica (pressão dos grandes grupos junto das autoridades centrais e locais), e social (melhoria das condições de vida das populações e surgimento do turismo de massas) assim o determinaram. Desta forma, o desenvolvimento turístico e urbanístico foi guiado pela iniciativa privada, tendo como prioridade a obtenção de lucros, sem preocupações a nível do ordenamento do território. A instalação do 
"progresso", nos anos de 1970-80, teve repercussões profundas no litoral, gerando graves problemas nos sistemas naturais, que põem em causa a sustentabilidade do turismo algarvio. Desde 1990, com o despontar das preocupações de carácter ambiental, a comunidade científica e as autoridades têm procurado estabelecer regras de gestão costeira efetiva e eficaz. Contudo, os POOCs e outros planos enfermam de limitações burocráticas e técnicas que dificultam a sua aplicação prática. Algumas dessas limitações prendem-se, por exemplo, com condições pré-estabelecidas e dificilmente revogáveis, com a influência económica de certos grupos com interesses no litoral e com a falta de vontade política na aplicação de medidas de verdadeiro carácter público, mas pouco populares e muito contestadas. No século XXI, a maior dificuldade continua a ser a efetiva aplicação prática do que é preconizado a nível legislativo em relação à proteção dos valores naturais do litoral. Embora muito tenha mudando, verifica-se que tal como nos anos de 1960 é grande a diferença entre as intenções de jure e as ações de facto.

\section{BIBLIOGRAFIA}

Andrade, C.; Viegas, A.; Tomé, A. \& Romariz, C. 1989. Erosão do Litoral cenozoico do Algarve. Geolis, III: 1-2: $261-270$

AsSEMBleIA DA REPÚBLICA 1965. Plano Intercalar de Fomento para 1965-1967, I, Proposta de Lei e Projeto. Lisboa, Imprensa Nacional.

ATAS DAS SESSÕES DA COMISSÃo CONSUltiVA DE URBANIZAÇÃO DO DISTRITO DE FARO 1969. Anexo n. ${ }^{\circ} 4$ à ata n. $^{\circ} 12$, Parecer sobre o sector 3 do Planeamento Regional do Algarve, não publicado [Centro de Documentação do Turismo].

BARLAVENTO 2009. Algarve tem 12 Projetos de Interesse Nacional (PIN) em diferentes fases, 28 de março.

BARLAVENTO 2009. É tempo de parar para pensar, $10 \mathrm{de}$ abril.

BRITO, C. 2005. 25 anos que mudaram o Algarve (O papel da CCR/CCDR no desenvolvimento algarvio). Faro, Edição CCDR.

Cavaco, C. 1969. Geografia e Turismo no Algarve. Aspetos Contemporâneos. Finisterra. Revista Portuguesa de Geografia, IV, 8: 216-272.

Cavaco, C. 1980. O Turismo em Portugal. Aspetos evolutivos e espaciais. Extrato de Estudos Italianos em Portugal, 40-41-42, Lisboa.

CNADS 2001. Reflexão sobre o Desenvolvimento Sustentável da Zona Costeira. Conselho Nacional do Ambiente e do Desenvolvimento Sustentável, Lisboa.

CT 1966. Planeamento turístico do Algarve. Relatório de Base. Comissariado do Turismo, Gabinete de Estudos e Planeamento. Não publicado [Centro de Documentação do Turismo].

DIÁRIO DA REPÚBLICA 1993. Decreto-lei n. ${ }^{\circ}$ 309/93 de 2 de setembro, I-A, (206).

DIÁRIO DA REPÚBLICA 1999. Resolução de Conselho de Ministros n. ${ }^{\circ} 33 / 99$, de 27 de abril, I-B (98).
DIÁRIO DA REPÚBLICA, 2009. Resolução de Conselho de Ministros n. ${ }^{\circ} 82,8$ de setembro, I (174).

DIAS, J.A. 1993. Estudo de avaliação da situação ambiental e proposta de medidas de salvaguarda para a faixa costeira portuguesa (Geologia costeira). Liga para a Proteção da Natureza. Disponível em: http:// w3.ualg.pt/ jdias/JAD/eb_Ambicost.html

DiAS, J.A. 2004. Evolução do conceito de Sedimento Relíquia. Disponível em: http://w3.ualg.pt/ jdias/JAD/ ebooks/Reliquias.pdf

DoDI, L. 1966. Plano Regional do Algarve. Anteplano. Não publicado [Arquivo da Direção Geral do Ordenamento do Território e Desenvolvimento Urbano].

DodI, L.; REGGIO; Morini \& Toshi 1964. Planeamento Urbanístico da Região do Algarve, Esboceto da Faixa Marginal. Memória Descritiva. Não publicado [Centro de Documentação do Turismo].

EXPRESSO 1977. Hotéis do Algarve estarão cheios no verão, 23 de dezembro.

EXPRESSO 1980. Saneamento básico do Algarve: levantamento das principais deficiências, 30 de agosto.

EXPRESSO 1985. No Algar Seco aldeamento turístico com alvará ilegal, 17 de agosto.

EXPRESSO 1985. Algar Seco: aldeamento turístico ameaça área natural classificada, 15 de outubro.

EXPRESSO 2006. Projeto Verdelago em reta final, 25 de agosto.

EXPRESSO Revista 1980. Jogos sem fronteiras: o Algarve, 31 de maio.

EXPRESSO Revista 1983. O Algarve do turismo "pobre", 10 de setembro.

EXPRESSO. ESPECIAL FÉRIAS 80 1980. Portimão: $70 \mathrm{mil}$ durante 3 meses, 25 mil durante 9, 13 de setembro.

FERNANDES, J.M. 1982. Algarve: à beira da catástrofe. Revista do Expresso, 24 de julho.

FERnANDES, J.M. 1984. Praias poluídas em Albufeira. Expresso, 31 de março.

Fernandes, J.M. 1985. Ponta da Piedade: um lobby contra a paisagem. Revista do Expresso, 4 de maio.

Freitas, J.G. 2010. O Litoral Português na Época Contemporânea: Representações, Práticas e Consequências. Os Casos de Espinho e do Algarve (c. 1851 a c. de 1990). Dissertação de Doutoramento, Faculdade de Letras da Universidade de Lisboa.

GONÇALVES, E.S. 1996. Turismo de massas e estruturação do território. Dissertação de Mestrado, Faculdade de Letras de Lisboa.

IDEALISTA NEWS 2015. Construção no Algarve em queda há uma década regista pior ano em 2014, 10 de março.

MAOTDR 2007. Litoral 2007-2013: Avaliação dos Planos de Ordenamento da Orla Costeira e propostas de atuação. Ministério do Ambiente, do Ordenamento do Território e do Desenvolvimento Regional, Lisboa.

MARQUES, F.M. 1997. As arribas do litoral do Algarve. Dinâmica, processos e mecanismos. Dissertação de Doutoramento, Faculdade de Ciências da Universidade de Lisboa.

MOPC 1964. Planeamento Urbanístico da Região do Algarve. Esboceto e orientação geral. Relatório do Gabi- 
nete Técnico do Plano Regional do Algarve. Ministério das Obras Públicas e Comunicações, Direção Geral dos Serviços de Urbanização. Não publicado [Centro de Documentação do Turismo].

PCM 1973. Projeto do IV Plano de Fomento, I, Metrópole. Presidência do Conselho de Ministros, Imprensa Nacional, Lisboa.

PorTAs, N. 1991. Crítica do urbanismo. O desenho urbano em situações de costa. Sociedade e Território. Revista de Estudos Urbanos e Regionais, 13 (5), junho.

REVEZ, I. 2016. Autarcas preocupados com demolições na Ria Formosa. Público, 12 de janeiro.

REVEZ, I. 2016b. Camaleões não evitam demolições na Ria Formosa. Público, 1 de abril.

Rosal, S. 1962. Discurso. Diário das Sessões da Assembleia Nacional, 2 de março. Imprensa Nacional, Lisboa.

Rosal, S. 1967. Discurso. Diário das Sessões da Assembleia Nacional, 25 de novembro. Imprensa Nacional, Lisboa.

SAnTos, C. 1965. Terra morena. Algarve do sonho e da realidade. Início, Lisboa.

SANTOS, F.D.; LOPES, A.M.; MONIZ, G.; RAMOS, L. \& TABORDA, R. 2014. Gestão da Zona Costeira. O desafio da mudança. Relatório do Grupo de Trabalho do Litoral. Não publicado. Disponível em: http://sniamb.apambiente.pt/infos/geoportaldocs/ docs/Relatorio_Final_GTL2015.pdf

SNI 1963. Plano de Valorização Turística do Algarve. Estudo preliminar. Secretariado Nacional de Informação, Direção de Serviços do Turismo, Lisboa. Não publicado [Centro de Documentação do Turismo].

SOARES, A.M. 1997. A urbanística do lazer e do turismo no Algarve litoral. Dissertação de Mestrado, Faculdade de Letras da Universidade de Lisboa.

SoAres, M. 2014. Pelo menos uma em cada dez casas na orla costeira está desocupada. Público, 1 de abril.

SCHMIDT, L. 2009. A lógica invertida. Expresso, 1 de novembro.

Schmidt, L.; SAntos. F.D; Prista, P; SARAiva, T. \& GoMES, C. 2012. Alterações climáticas, sociais e políticas em Portugal: processos de governança num litoral em risco. Ambiente \& Sociedade, XV (1): $23-40$

Turismo DO ALgARVE 2014. Algarve conjuntura turística. Boletim trimestral, 4 março.

Villalobos, L. \& Revez, I. 2015. No Algarve, um em cada três empréstimos às empresas está em incumprimento. Público, 9 de dezembro. 